\title{
MIDAS
}

Museus e estudos interdisciplinares

$3 \mid 2014$

Varia e dossier temático: "Museos y participación biográfica"

\section{María Acaso - Perspectivas: Situación Actual de la Educación en los Museos de Artes Visuales}

\section{Susana Gomes da Silva}

\section{OpenEdition}

\section{Journals}

Edição electrónica

URL: http://journals.openedition.org/midas/459

DOI: $10.4000 /$ midas. 459

ISSN: 2182-9543

\section{Editora:}

Alice Semedo, Paulo Simões Rodrigues, Pedro Casaleiro, Raquel Henriques da Silva, Ana Carvalho

\section{Refêrencia eletrónica}

Susana Gomes da Silva, « María Acaso - Perspectivas: Situación Actual de la Educación en los Museos de Artes Visuales », MIDAS [Online], 3 | 2014, posto online no dia 09 junho 2014, consultado no dia 22 setembro 2020. URL : http://journals.openedition.org/midas/459 ; DOI : https://doi.org/10.4000/ midas.459

Este documento foi criado de forma automática no dia 22 setembro 2020.

\section{(1) $\$(0)$

Midas is licensed under a Creative Commons Attribution-NonCommercial-ShareAlike 3.0 International License 


\title{
María Acaso - Perspectivas: Situación Actual de la Educación en los Museos de Artes Visuales
}

\author{
Susana Gomes da Silva
}

\section{REFERÊNCIA}

Acaso, María, coord. 2011. Perspectivas: Situación Actual de la Educación en los Museos de Artes Visuales. Madrid: Fundación Telefónica e Editorial Ariel. 192 páginas, ISBN 978-84-08-10260-1.

1 Este livro ${ }^{1}$ é simultaneamente um reflexo de e um contributo para o processo de mudança vivido nas últimas décadas no campo da educação nos museus de artes visuais em Espanha, assumindo-se não como um repositório de respostas e soluções, mas como um espaço compilador de problemáticas, desafios e perspetivas, um território questionador e frutífero para a reflexão sobre os efeitos e os rumos de um campo e uma profissão em profunda redefinição e transformação, um lugar para pensar, desenhar e desejar o seu (nosso) futuro.

\section{Mudança educativa - questões e interlocutores}

Os últimos anos têm sido palco de um verdadeiro giro educativo em Espanha (e não só), uma mudança (ou melhor, um conjunto importante de mudanças e movimentos) que confere uma maior atenção à educação e uma crescente visibilidade aos departamentos educativos e suas profissionais ${ }^{2}$.

Um olhar mais detalhado sobre este giro educativo mostra, no entanto, que apesar de se constituir inegavelmente como uma conquista considerável, é importante colocar em evidência as contradições e paradoxos, mas também as ambições e desejos, de uma carreira secundarizada, de contornos indefinidos e precários, ainda marginada y 
desestimada, não obstante o aparente crescimento e centralidade nos novos espaços e tendências museológicas. Na verdade podemos fazer eco da pergunta de Eneritz López e Eva Alcaide: «¿Quién planeó ser de mayor educadora en museos?» (p. 21) e seguramente teríamos que responder ninguém, uma vez que ser educadora de museu é ainda, pese à sua proliferação, uma carreira sem definição profissional reconhecida.

4 A presente obra oferece assim uma leitura e interpretação desta mudança, seus efeitos e desafios, contextualizando-a na realidade histórica e política espanhola, «olhando para trás para poder seguir em frente», e expondo e analisando, a várias vozes e múltiplas mãos, o momento presente para nele (e na sua multiplicidade de realidades, atores, convicções e forças) fundar e projetar a mudança desejada e possível. Tal como nos explica a coordenadora do livro, María Acaso, uma vez assumida a evidência desta mudança educativa, há que perguntar:

¿qué podemos hacer ahora?, ¿hacia dónde es necesario trabajar desde esta recién estrenada visibilidad?, ¿qué perspectivas se abren ante nuestro futuro? y, sobre todo, ¿cómo cambiar el paradigma modernista en el que la educación se encuentra anclada $y$ conectar con la realidad social posmoderna, transformando el museo de meta en micronarrativa? (p. 31)

5 E é nesta vontade de pensar o estado presente (na sua polifonia, dinamismo e diversidade) para desenhar rumos e caminhos de futuro que se fundam as opções metodológicas que estruturam a organização da obra, a seleção de textos e de autoras (representantes de algumas das instituições artísticas e académicas mais relevantes de Espanha). Reflexão esta que inclui ainda o projeto de investigação sobre a formação das educadoras de museus de artes visuais levado a cabo pela Universidade Complutense de Madrid, sob orientação de María Acaso, e do qual resulta um conjunto muito interessante de entrevistas e posicionamentos face a duas questões essenciais, que se enunciam sob a forma de perspetivas/tendências no capítulo final: que problemáticas enfrenta atualmente a carreira e a formação das educadoras de museus de artes visuais? Qual seria a situação ideal para esta mesma formação?

6 Estas duas questões, que enformam todo o projeto de investigação e que, de alguma forma, ajudam a orientar o futuro da profissão, funcionam na realidade como as linhas mestras de toda a reflexão que perpassa o livro e permitem não perder de vista o fio condutor que orientou toda a pesquisa, para além do projeto de investigação propriamente dito. Por outro lado, marcam as duas vertentes sobre as quais se constrói uma visão de conjunto, presente sobretudo nos capítulos de análise mais abrangente e de síntese da coordenadora da obra: uma visão e um discurso construído sempre entre o presente e o futuro, entre o real e o desejado, a partir de um posicionamento crítico, mas otimista e construtivamente implicado. Implicado porque desenhado a partir do olhar e da prática daquelas que nele ativamente se integram e trabalham, quer enquanto investigadoras quer enquanto educadoras, assumindo-se como agentes, simultaneamente motor e matéria prima do processo de mudança. E é neste sentido que o conjunto de reflexões resultante, ainda que histórica e geograficamente situadas em realidades e contextos específicos espanhóis, assumem um lugar de questionamento e pensamento alargado em termos de conceitos e problemáticas, permitindo uma reflexão transferível para outras realidades, como é o caso da portuguesa que partilha atualmente de um mesmo momento de reinvenção do papel da educação nos museus e seus interlocutores. 


\section{Estrutura e conteúdos}

7 Estruturalmente, a obra organiza-se em quatro partes:

8 I. «Hojas de ruta» - uma história sobre os departamentos educativos e as educadoras nos museus espanhóis que permite uma compreensão alargada, crítica e reflexiva das origens e evolução deste campo e suas agentes profissionais, lançando algumas pistas para as linhas de ação e de mudança presentes ao longo do livro;

9 II. «Puntos de vista» - capítulo que recolhe as reflexões de diferentes autoras, representantes de várias instituições académicas e museológicas em Espanha, sobre fundamentos do comissariado educativo; sobre projetos educativos inovadores; sobre o cruzamento entre arte, tecnologia e museus, um campo promissor de transformação da relação com os públicos e do seu espaço de participação; sobre outros lugares e experiências;

10 III. «Preguntas retóricas» - o projeto de investigação qualitativa em torno da formação ideal das educadoras de museus de artes visuais, levado a cabo de forma independente por uma equipa de investigadores do Grupo de Investigação do Museu Pedagógico de Arte Infantil (GIMUPAI) da Universidade Complutense de Madrid. Uma investigação conduzida através de entrevistas a 25 profissionais da área, autores dos textos do capítulo II e formadores na área da educação nos museus;

11 IV. «Perspectivas» - síntese das principais linhas resultantes quer do projeto de investigação quer dos capítulos precedentes organizadas sob a forma de perspetivas que enquadram quer o papel e competências da educadora de museu e sua formação, quer o papel dos departamentos educativos e sua orgânica de trabalho.

\section{Um mapa organizador da leitura}

O conjunto de capítulos, depoimentos, temas e perspetivas requer, no entanto, pela sua grande multiplicidade, uma leitura transversal capaz de relembrar as linhas de força de análise e reflexão que estruturam o esqueleto ideológico da obra, muitas vezes obrigando a uma (re)leitura cruzada de capítulos em partes distintas. E é neste sentido que, mais do que proceder a um resumo das principais ideias contidas nesta multiplicidade de artigos, visões, experiências e projetos (um resumo que seria inevitavelmente redutor e uniformizador de perspetivas que muitas das vezes são díspares e contraditórias) me parece mais importante salientar o que nos ajuda justamente a navegar crítica e construtivamente através da diversidade de olhares apresentada. Para isso, apresento as linhas propostas pela própria coordenadora da obra para o desenho de uma espécie de mapa organizador que lança luz sobre as problemáticas abordadas, elencando-as em seis pontos-chave:

1) as que se abrem sobre o desenvolvimento de modelos teóricos para a aplicação do comissariado educativo para esta nova etapa;

2) as que se materializam na realização de projetos na realidade quotidiana dos museus;

3) as que se desdobram na interseção entre a educação, a arte e a tecnologia;

4) as que se abrem relativamente à formação e competências que deve ter a educadora;

5) as que se relacionam com o problema do peso e da importância real ou fictícia do educativo nos museus de artes visuais; 
6) aquelas que remetem para a importância da memória, da reflexão e da investigação como práticas quotidianas.

E é, a meu ver, sobretudo no artigo de Maria Acaso «Del paradigma modernista al "posmuseo": seis retos a partir del giro educativo (¿Lo intentamos?)» (p. 30-37), que este elenco de problemáticas ganha verdadeira utilidade, uma vez que a autora enuncia a partir dele um conjunto de desafios (aqui mantidos no seu enunciado na língua original) conducentes a uma prática reflexiva e verdadeiramente transformadora, útil para além do contexto específico espanhol ao qual se aplica:

14 a) sob o título «Propuestas felices para el comisariado de educación: de las pedagogías críticas a las pedagogías regenerativas», Acaso propõe que se opere uma mudança de paradigma, um reposicionamento, uma passagem da visão pessimista da pedagogia crítica (o modelo ainda maioritariamente vigente nos departamentos educativos espanhóis e aquele, que curiosamente, continua a ser apontado pelos profissionais nas entrevistas como o modelo de referência a manter), segundo a autora «antiempowering, antiempoderador, o antiimpulsor» (p. 32) para o otimismo feliz das pedagogias regenerativas que incidem na participação e que se poderiam chamar de ações aproveitadoras (p. 32). Aquelas que, de alguma forma, enfrentam os sistemas de opressão, desigualdade, não por negação ou por recusa, mas pelo fomento de um movimento de reforço e de maior espaço conferido às tendências emergentes, de modo a que estas, no seu crescimento possam «agotar las fuentes de energía de las relaciones/estructuras opresivas y habituales» (p. 32). Esta mudança de atitude e de paradigma de pensamento e atuação permite, assim, de forma positiva e construtiva quebrar mais facilmente os ciclos de desigualdade, subalternização e precariedade inscritos na história das origens dos departamentos educativos e das educadoras de museus e seus papéis, uma história (tal como nos é apresentado no início da obra) assente em sistemas de marginalidade, fragmentação e indefinição e que importa refazer através de uma mudança de papel: a educadora assumida como uma produtora cultural (p. 161) e intelectual transformativa (p. 163), agente de um comissariado educativo efetivo;

b) «Mirar como acto de creación: sobre la necesidad de cambio de las arquitecturas pedagógicas y la necesidad de explicitar lo invisible»;

16 Perguntemo-nos de forma consciente: trabalhamos nos museus de acordo com as teorias que ensinamos? Salientando os paradoxos de propostas que acabam por não romper com a relação hierarquizada do saber herdada do paradigma modernista, a autora chama aqui a atenção para a necessidade de mudar não apenas os conteúdos, mas também a arquitetura do saber. Nas suas palavras, «El reto al que nos enfrentamos, si queremos ir más allá de lo superficial en el giro educativo, consiste también en cambiar la arquitectura pedagógica de nuestras acciones», nomeadamente em dois campos principais (p. 34):

17 - começar a assumir o ato de olhar como um ato criativo no qual o observador é participante e gerador de saber, posicionamento que leva a questionar o que significa realmente a participação por parte das audiências, um tema cada vez mais na ordem do dia, assim como as formas e modificações necessárias para que esta mudança de perspetiva e de relação com os públicos ocorra efetivamente;

18 - assumir que a linguagem visual não é uma estratégia de comunicação, nem de representação, mas sim um sistema de transformação e de performação da realidade que opera de maneira invisível na agência do espetador e que é necessário explicitar e 
tornar visível para «empezar a jugar limpio» (p. 34). Isto implica «asumir el poder performativo (transformativo de lo social) del lenguage visual, un cambio que nos llevaría a dejar de entenderlo como un sistema de representación para entenderlo como una fuerza de transformación» (p. 34). Ou seja, uma força de transformação da realidade que impõe, formata, cria, performa o nosso corpo, ideias, hábitos, referentes e que os museus de artes visuais necessitam de tornar visível e trabalhar enquanto uma das mais poderosas ferramentas para transformar a agência do espetador, e na realidade os próprios sistemas de leitura em que assenta toda a sua prática educativa $\mathrm{e}$ pedagógica.

c) «De la "monitora de tiempo libre" a la (no)educadora»;

Uma vez questionada e alterada a arquitetura pedagógica modernista cumpre pensar qual o papel da educadora de museus? Num contraponto ao papel historicamente desempenhado por esta figura profissional, segundo a autora, o seu papel passa a ser atualmente o de fazer esta mudança do paradigma, o de deixar de «concebir el museo como un relato para transformarlo en un contrarelato», deixar de ser monitora para ser (no)educadora (p. 36). E é no conceito de (no)educadora que podemos ver aplicados, de forma mais radical, algumas das mudanças esboçadas anteriormente e com efeitos cruciais quer ao nível das práticas quer ao nível da formação, um dos temas centrais de toda esta obra. De acordo com Acaso, uma (no)educadora trabalha com:

21 - uma pedagogia aberta, horizontal e fundamentalmente colaborativa;

22 - (no)visitantes: concebidos como visitantes que não só olham e aprendem como também criam e ensinam numa relação de horizontalidade e paridade, num processo colaborativo e partilhado de construção de saber;

23 - uma (no)aula: porque todo o perímetro do museu se constitui em zona de aprendizagem;

24 - (no)materiais: porque até os próprios corpos dos participantes no processo educativo se transformam em material de trabalho.

25 Esta reflexão relança a questão da formação e do perfil de competências destes agentes de mudança e serve também de pano de fundo a algumas das perspetivas enunciadas nas conclusões do último capítulo. Isto é, requer uma total redefinição quer das competências e saberes necessários ao exercício da sua função quer do enunciado das suas principais competências, exigindo das universidades um sistema de formação descentrado e pós universitário, capaz de responder ao desafio fora da arquitetura tradicional dos campos de estudo instituídos.

26 d) «Sobre los peligros de la "estetificación" de lo pedagógico: de lo educativo como cebo a lo educativo como medula»;

27 Numa chamada de atenção e convite à responsabilização pelo que queremos que seja de facto a preponderância da educação no campo dos museus, a autora dá voz a importantes inquietudes: será real a situação de centralidade e visibilidade dos departamentos educativos? Como passar a fazer com que a educação constitua verdadeiramente a coluna vertebral dos museus? Como evitar a tentação da sua instrumentalização?

28 De facto, uma vez assumida a importância do giro educativo torna-se crucial pensar o que fazer desta visibilidade e centralidade, combatendo aquilo que Irit Rogoff designa como «el peligro de la estetificación de lo pedagógico» (p. 36). Este posicionamento permite ler e relançar os desafios que enfrentam os departamentos educativos em 
crescimento e a redefinição tal como comprova a investigação levada a cabo nesta obra, nomeadamente na sua orgânica de funcionamento dentro das instituições como um corpo e não como um apêndice periférico e/ou subalterno e no seu papel de intervenção nos sistemas de poder e transformação;

e) «De la sobreproducción a la necesidad de memoria, de reflexión y de investigación sobre lo recordado»;

E por fim, uma chamada de atenção sobre a necessidade de refletir sobre a investigação, seus modelos, processos e papéis e sua necessária centralidade num campo que passou as últimas décadas a criar atividades que lhe dessem visibilidade e centralidade mais que a produzir reflexão, registo e arquivo sobre esses mesmos processos e experiências. Na perspetiva de María Acaso, já não basta centrarmo-nos em educar, é necessário investigar sobre como e porque o fazemos, num questionamento crítico que recai sobre o próprio processo de investigação para o fazermos: que ferramentas são melhores para a investigação em educação nos museus? Que sistemas de recolha de dados são mais úteis? Como configurar uma epistemologia da investigação da educação nos museus capaz de responder a estas questões de forma qualitativa e polissémica?

O projeto de investigação apresentado nesta obra pretende, assim, ser simultaneamente um manifesto ao nível das metodologias qualitativas de investigação e um importante contributo para o enriquecimento deste arquivo que permite o registo e a produção de saber de forma consistente e perdurável.

A assunção da centralidade do processo de investigação focado nos próprios agentes da educação nos museus e no seu papel simultâneo de sujeitos de estudo e produtores de conhecimento reflexivo tem implicações importantes que permitem reforçar o reconhecimento profissional da educação nos museus enquanto carreira e desenhar paradigmas educativos consistentes. Além disso, contribui para um corpo de estudos capaz de, parafraseando uma das conclusões finais, formar profissionais criativas, com conhecimentos pedagógicos contemporâneos e com um posicionamento reflexivo tanto ao nível pessoal como institucional, que trazem paixão ao que que fazem e que consideram o seu trabalho ao mesmo nível que o discurso do comissariado, que têm em conta a investigação como parte da sua atividade quotidiana e são proficientes em línguas e técnicas digitais (p. 166).

À luz destas problemáticas o presente livro funciona como uma ferramenta de trabalho útil a qualquer educadora de museus, elencando alguns dos rumos possíveis para uma mudança e deixando um convite a que encetemos já esta mesma transformação: «Lo intentamos?»

\section{NOTAS}

1. Além da versão impressa existe uma versão digital da publicação disponível através do seguinte endereço eletrónico: http://www.fundacion.telefonica.com/es/arte_cultura/ publicaciones/detalle/98 
2. Usarei aqui a nomenclatura no feminino tal como o faz assumidamente a coordenadora do livro, uma vez que reforça a assunção da feminização desta profissão, situação que é em parte também responsável pela sua secundarização e inscrição em sistemas desigualitários de reconhecimento e de poder.

\section{AUTORES}

\section{SUSANA GOMES DA SILVA}

Centro de Arte Moderna - Fundação Calouste Gulbenkian, Portugal, ssilva@gulbenkian.pt 